\title{
Tissue Valve Replacement for Severe Calcified Pulmonary Stenosis: First time in BSMMU
}

\author{
REZWANUL HAQUE BULBUL ${ }^{1}$, OMAR SADEQUE KHAN ${ }^{1}$, MOHAMMAD SAMIR AZAM SUNNY ${ }^{1}$, SWADESH \\ RANJAN SARKER ${ }^{1}$, MOSTAFA NURUZZAMAN², NAJEEB AHSAN ${ }^{2}$ \\ ${ }^{1}$ Department of Cardiac Surgery, Bangabandhu Sheikh Mujib Medical University, Shahbagh, Dhaka, ${ }^{2}$ Department of \\ Anaesthesia, Analgesia and critical care medicine, Bangabandhu Sheikh Mujib Medical University, Shahbagh, Dhaka.
}

Address for Correspondence: Dr. Rezwanul Haque Bulbul, Associate Professor, Department of Cardiac Surgery, Bangabandhu Sheikh Mujib Medical University, Shahbagh, Dhaka, E-mail: drhbulbul@yahoo.com

\begin{abstract}
:
Pulmonary valve replacement for pulmonary regurgitation is a common practise. Pulmonary stenosis relief or after release of right ventricular outflow tract obstruction, progressive pulmonary regurgitation leading to biventricular failure is a big problem. If early pulmonary valve replacement done by homograft or tissue valve then we can overcome this problem. In our case report we have done pulmonary valve replacement by Edward life science Tissue valve for calcified pulmonary valve. And our patient showed a good response after valve replacement.
\end{abstract}

\section{Introduction:}

Isolated pulmonary stenosis (PS) relief or relief of right ventricular (RV) outflow tract obstruction in tetralogy of Fallot or similar physiology often results in pulmonary regurgitation (PR). ${ }^{1}$ The resultant chronic volume overload can lead to RV dilation, biventricular dysfunction, heart failure symptoms, arrhythmias, and sudden death. Pulmonary valve replacement (PVR) can lead to improvement in functional class and a substantial decrease or normalization of RV volumes. ${ }^{1,2}$ Other potential benefits of PVR are improvement in exercise capacity. Calcification of the pulmonary valve visible with routine roentgenographic methods is unusual. Associated defects, especially ventricular septal defect, are common. Recognition is a major problem due to confusion with other lesions, especially calcific aortic stenosis. Longstanding elevation of right ventricular pressure appears essential for the deposition of calcium. The role of aging and healed bacterial endocarditis in the etiology is uncertain. ${ }^{3}$

\section{Case report:}

Mr. Akter Hossain 20 yrs old male farmer admitted on 08.12.2012 under green unit of Cardiac Surgery with the complaints of palpitation and respiratory distress for 1year, small joint swelling of hand and feet for 12 years. On examination the patient was short stout with average body built, there was systolic thrill over the pulmonary area. First heart sound normal, Second heart sound soft, there was systolic murmur best heard in pulmonary area. Lungs clear with no added sound. ECG showed heart rate 85/ min, regular with right ventricular hypertrophy with strain pattern. Chest X-ray shows cardiomegaly. Colour Doppler echocardiogram showing severe pulmonary stenosis with calcification of valve (PPG: $204.3 \mathrm{mmHg}$ ), Pulmonary valve annulus $10 \mathrm{~mm}$, main pulmonary artery $10 \mathrm{~mm}$ diameter.

The patient was operated on 27.12.2012. Under general anaesthesia, with all aseptic precautions median sternotomy done. After thymus dissection pericardiotomy done. Cardiopulmonary bypass was established with bicaval cannulation. Heart was arrested by giving cross clamp and antegrade cardioplegia under mild hypothermia $\left(32^{\circ} \mathrm{C}\right)$. Dissection of pulmonary artery done along with ligation of fibrous band on aortopulmonary groove. RAtomy and PAtomy done. PFO found and vent given through PFO. Pulmonary valve was found severely stenosed, pinhole and calcified. Total excision of pulmonary valve done. Hager's dilator $(20 \mathrm{~mm})$ easily passed through RVOT. Pulmonary annulus was enlarged by giving incision extending upto infundibulum. Then

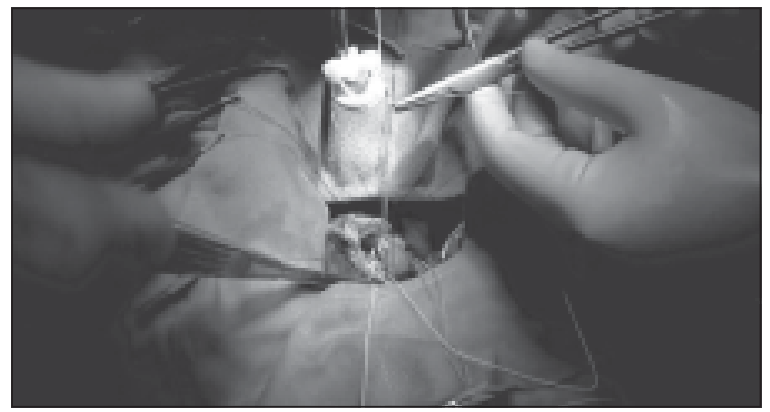

Fig.-1: Pulmonary Valve Replacement with Tissue Valve (19mm Edward life science porcine Valve). 


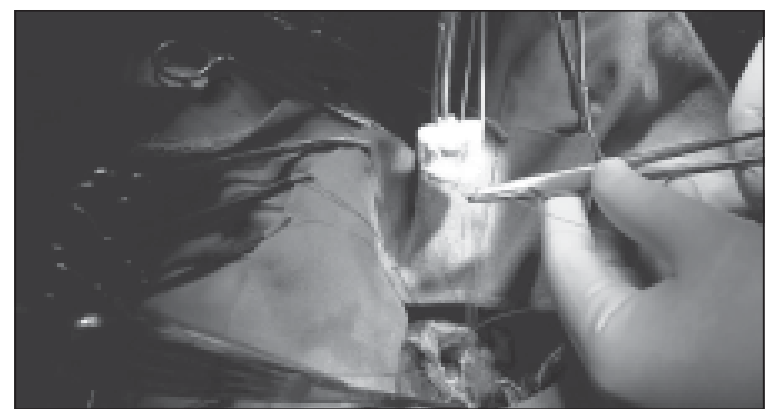

Fig.-2: Pulmonary Valve Replacement with Tissue Valve (19mm Edward life science porcine Valve).

glutaraldehyde $(0.6 \%)$ treated pericardium sutured to the infundibulum and annulus, creating a new enlarged annulus with 4/0 double ended prolene. 19mm Edward life science porcine aortic valve was taken for thawing. $100 \mathrm{ml}$ normal saline taken in 2 gully pot. 3 mins rinsing done in each. Then 19mm Edward life science porcine aortic valve was placed in pulmonary supraannular position and sutured to the newly created annulus by interrupted pledgeted stitch with 4/0 double ended prolene. Some Pledget was placed outside the pericardium. Some pledget inside the PA. PA closed with the rest of the pericardium by continuous stitch. Then RA closed. Patient weaned from CPB without any difficulty. X-clamp time-105 min, Total bypass time-165 min. After achieving haemostasis chest was closed leaving two right ventricular epicardial pacing wire and two mediastinal chest drain (retrocardiac $32 \mathrm{Fr}$ and right pleural $32 \mathrm{Fr}$ ) tubes attached with underwater seal drain bags. The patient was shifted to the intensive care unit with minimum inotropic support. Patient was extubated on the same day, shifted to general ward on the $3^{\text {rd }}$ post operative day and discharged home on the $10^{\text {th }}$ postoperative day. The patient remains asymptomatic on the subsequent follow up. The patient is on minimum medication and leading a normal life.

\section{Discussion:}

If PVR can be performed with negligible mortality and morbidity, and durable prosthetic valves are available, PVR should be done as early as possible for all patients with dilated RV. PVR should be performed before irreversible RV dysfunction occurs ${ }^{1}$. In our case report we are trying to show that pulmonary valve replacement can be an ideal choice for pulmonary valve calcification with near normal RV volumes and function. When an early PVR is advocated, an important issue is the need for future reoperations for a failing homograft or tissue valve, the most commonly used type of valve replacement. The decrease in right ventricular volumes after PVR has to be weighed against the risk of subsequent homograft or tissue valve failure. ${ }^{5}$ The current guideline is the onset of symptoms, progressive RV dilation, progressive tricuspid valve regurgitation or diminishing exercise tolerance are indications for pulmonary valve replacement ${ }^{5}$. In our case, our patient had progressive RV dilatation with moderate tricuspid regurgitation and exercise intolerance. ${ }^{1,4}$ The insertion of a competent pulmonary valve in young patients significantly improves pulmonary regurgitation (PR) and reduces the end diastolic dimension of the right ventricle. Reduction of RV size was associated with reduced tricuspid regurgitation and improved functional capacity. ${ }^{1}$ In our case report also support this data.

\section{References:}

1. Lee C, Kim YM, Lee CH, kwak JG, Park CS, Song JY et al. Outcomes of Pulmonary Valve Replacement in 170 Patients With Chronic Pulmonary Regurgitation After Relief of Right Ventricular Outflow Tract Obstruction: Implications for Optimal Timing of Pulmonary Valve Replacement, J Am Coll Cardiol 2012; 60: 1005-14.

2. Fiore AC, Rodefeld M, Turrentine M, Vijay P, Reynolds T, Standeven J et al. Pulmonary Valve Replacement: A Comparison of Three Biological Valves, Ann Thorac Surg 2008;85:1712-8.

3. Rodriguez GR, Bennett KR, Lehan PH, Calcification of the Pulmonary Valve, CHEST 1971; 59:160-4.

4. Kogon B, Plattner C, Kirshbom P, Kanter K, Leong T, Lyle T et al. Risk factors for early pulmonary valve replacement after valve disruption in congenital pulmonary stenosis and tetralogy of Fallot, J Thorac Cardiovasc Surg 2009;138:103-8.

5. Mulder BJM, Winter RJD, Wilde AAM, Pulmonary valve replacement: A new development in the life time strategy for patients with congenital heart disease, Netherlands Heart J, 2007; 15:1:3-4. 